\title{
Uso de fitase em dietas de diferentes granulometrias para frangos de corte na fase inicial
}

\author{
Phytase use in diet with different particle size for broiler chicken at initial stage
}

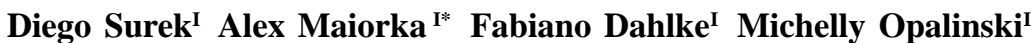 \\ Sebastião Gonçalves Franco ${ }^{I}$ Everton Luis Krabbe ${ }^{I}$
}

\section{RESUMO}

Neste estudo foi avaliada a adição da enzima fitase (500FTU $\mathrm{kg}^{-1}$ ) em dietas de diferentes granulometrias (Diâmetro Geométrico Médio - DGM) para frangos de corte na fase inicial. As aves foram distribuidas em um delineamento experimental inteiramente ao acaso, em esquema fatorial 2 (DGM - 680

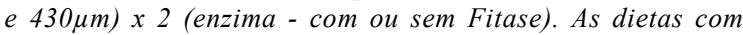
inclusão de fitase tiveram uma redução de 10,5\% de Ca e $22 \%$ de $P$ em relação à dieta basal sem fitase. Foram avaliados desempenho (consumo de ração, ganho de peso e conversão alimentar), o coeficiente de metabolizabilidade da matéria seca, a proteina bruta, a energia bruta e também o coeficiente de biodisponibilidade do cálcio e do fósforo. As aves que receberam dietas com DGM $680 \mu \mathrm{m}$ apresentaram maior ganho de peso (798g) e melhor conversão alimentar (1,330 $\left.\mathrm{kg} \mathrm{kg}^{-1}\right)$ quando comparadas às aves alimentadas com dietas de DGM $430 \mu \mathrm{m}$ (780g e 1,390kg para ganho de peso e conversão alimentar, respectivamente) $(P<0,05)$. Essas aves também apresentaram maior coeficiente de metabolizabilidade e biodisponibilidade para proteína, cálcio e fósforo, respectivamente. A utilização de fitase, em dieta com diminuição do $\mathrm{Ca}$ e $\mathrm{P}$, promoveu desempenho das aves similar às dietas basais, bem como melhorou os coeficientes de metabolisabilidade $e$ biodisponibilidade de proteina e de cálcio e fósforo nas dietas de menor granulometria. Conclui-se que a conversão alimentar é melhorada quando utilizadas dietas de maior granulometria. A utilização de fitase aumenta a eficiencia de uso de nutrientes da ração e melhora o desempenho de frangos de corte.

Palavras-chave: desempenho, frangos, fitase, granulometria.

\section{ABSTRACT}

The addition of fitase enzyme (500FTU $\left.\mathrm{kg}^{-1}\right)$ was evaluated, in diets of different particle size (Average Geometric Diameter - AGD) for broiler chicken at the initial phase. Birds were distributed in a totally randomized experimental design,

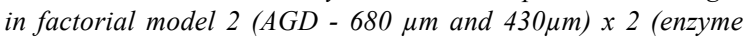
- with or without Fitase). Diets with fitase inclusion presented a reduction of $10.5 \%$ of $\mathrm{Ca}$ and $22 \%$ of $\mathrm{P}$ compared to basal diet without fitase. Performance was evaluated (feed intake, weight gain and feed conversion), the metabolisability coefficient of the dry matter, net protein, net energy and also biodisponibility coefficient, calcium and phosphorus. Birds that received diets

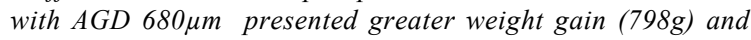
better feed conversion $\left(1,330 \mathrm{~kg} \mathrm{~kg}^{-1}\right)$ when compared to birds fed with diets of DGM 430 $\mathrm{mm}(780 \mathrm{~g}$ and $1,390 \mathrm{~kg}$ for weight gain and feed conversion, respectively) $(P<0.05)$; higher metabolisability of protein and biodisponibility coefficient of calcium and phosphorus. The use of fitase, in diet with reduction of $\mathrm{Ca}$ and the P, promoted a bird's similar performance to basal diets, as well as it improved the metabolisability coefficient of protein and biodisponibility of calcium and phosphorus in the diets of smaller mash. In conclusion, feed conversion is improved when smaller particle size diets are used. Utilization of fitase increases the efficiency of use of nutrients in the ration and improves broiler chicken performance.

Key words: chicken, particle size, performance, phytase.

\section{INTRODUÇÃO}

A otimização do uso dos alimentos empregados na nutrição animal tem como finalidade melhorar o aproveitamento dos nutrientes e, conseqüentemente, reduzir os custos de produção. Entre eles, o fósforo é indicado como o terceiro componente mais caro em uma ração para frangos, ficando atrás somente da energia e da proteína, particularmente dos aminoácidos sulfurados (BOLLING et al., 2000). Nos alimentos de origem vegetal, o fósforo está presente, em grande quantidade, na forma química de fitato, que é de baixa disponibilidade e quelante de alguns cátions bivalentes como $\mathrm{Ca}, \mathrm{Fe}, \mathrm{Mg}, \mathrm{Zn}$,

\footnotetext{
'Departamento de Zootecnia, Universidade Federal do Paraná (UFPR). Rua dos Funcionários, 1540, 80035-050, Curitiba, PR,
} Brasil. E-mail: amaiorka@fpr.br. *Autor para correspondência. 
tornando-se um fator antinutricional. Isso pode ser atenuado pela administração de enzimas exógenas, pois a fitase apresenta a capacidade de hidrólise deste complexo, aumentando a biodisponibilidade e reduzindo a presença destes minerais nas excretas.

Um importante fator relacionado à nutrição $\mathrm{e}$ alimentação de aves, além da composição nutricional da dieta, é a estrutura física dos alimentos, que induz acentuadas alterações nos parâmetros metabólicos no consumo de alimentos, na capacidade de esvaziamento e pH do trato gastrintestinal, na atividade de enzimas digestivas e também no comportamento alimentar (ZANOTTO et al., 1994; DAHLKE etal., 2001; DAHLKE et al., 2001). Estas características físicas são dadas pela relação volume: peso, pelo tamanho das partículas, expresso pelo diâmetro geométrico médio (GMD), e pela variação no tamanho das partículas, descrito pelo desvio padrão geométrico (DPG), em que o menor valor corresponde à maior uniformidade das partículas. As aves apresentam uma preferência no consumo das rações com textura mais grosseira, seguido da textura média à textura fina (DAHLKE et al., 2001), tendo grande influência na regulação do consumo. Dessa forma, este trabalho teve como objetivo avaliar a interação entre os fatores adição de fitase e DGM do milho sobre o desempenho e a metabolisabilidade de alguns nutrientes em frangos durante a fase inicial.

\section{MATERIAL E MÉTODOS}

Foram utilizados 200 pintos de corte machos da linhagem $\operatorname{Ross}^{\circledR}$, de 1 dia de idade, alojados em baterias com boxes de dimensões de $0,98 \times 0,90 \times 0,50 \mathrm{~m}$ (comprimento $\mathrm{x}$ largura $\mathrm{x}$ altura) submetidos às mesmas condições ambientais (luz contínua de 24 horas de luz, ração e água ad libitum durante todo o período experimental). Utilizou-se um delineamento experimental inteiramente casualizado em esquema fatorial $2 \times 2$ (DGM x fitase) com quatro tratamentos e cinco repetições contendo 10 aves. Os tratamentos foram distribuídos da seguinte forma: $\mathrm{T} 1$ - ração de DGM $680 \mu \mathrm{m}$ contendo fitase $\left(500 \mathrm{FTU} \mathrm{kg}^{-1}\right)$; T2 - ração de DGM 430 $\mu$ m com fitase (500FTU kg-1); T3 - ração de DGM $680 \mu \mathrm{m}$ sem a adição de fitase e T4 - ração de DGM 430 $\mu \mathrm{m}$ sem fitase.

As dietas utilizadas, fornecidas na forma farelada, foram à base de milho e farelo de soja, sendo que aquelas contendo fitase tiveram uma redução de $10,5 \%$ de $\mathrm{Ca}$ e $22 \%$ de $\mathrm{P}$ disponível (Pd) em relação à dieta basal sem fitase. A enzima utilizada (Natuphos 5000, Basf Nutrição Animal, São Bernardo do Campo, São Paulo), obtida por fermentação por meio de fungos (Aspergillus niger), foi utilizada na quantidade de 500 FTU/kg de ração.

As diferentes granulometrias da dieta foram obtidas, por meio da moagem do milho em moinho tipo martelo, utilizando peneiras com furos de 4,0mm e 8,0mm de diâmetro. O diâmetro geométrico médio (GMD) foi determinado conforme procedimento descrito por ZANOTO \& BELLAVER (1996): uma amostra de 100g da ração foi seca em estufa a $105^{\circ} \mathrm{C}$, por 12 horas, peneirada em um conjunto de seis peneiras, com aberturas de $0,15,0,30,0,60,1,0,2,0$ e 4,0mm, sobrepostas, acopladas em um equipamento de vibração do tipo "Produteast", por 10 minutos, com $80 \%$ da velocidade vibratória máxima. A porcentagem da amostra retida em cada peneira foi multiplicada pelo fator $\mathrm{K}$ (valores convencionados e constantes). Os valores de cada peneira foram somados e divididos por 100. O valor obtido, chamado de Módulo de Finura (MF), é utilizado na seguinte fórmula: GMD: 104,14 x $(2)^{\mathrm{MF}} \mathrm{mm}$.

Foram avaliados consumo de ração (CR), ganho de peso (GP) e conversão alimentar (CA) no período de um a 21 dias de idade. O coeficiente de metabolisabilidade da matéria seca (MS), da proteína bruta (PB), da energia bruta (EB) e do coeficiente de biodisponibilidade do cálcio $(\mathrm{Ca})$, do fósforo $(\mathrm{P})$ foram determinados dos 18 aos 21 dias de idade, pelo método de colheita total. As determinações de MS, PB, Ca e P nas rações e excretas foram realizadas de acordo com recomendações daAOAC (1990) e a EB foi determinada pela combustão total da amostras usando bomba calorimétrica. As médias obtidas foram submetidas à análise de variância com auxílio do pacote estatístico SAS (1996) e, quando houve diferença estatística, as médias foram submetidas ao teste de Tukey a 5\% de significância.

\section{RESULTADOS E DISCUSSÃO}

Os resultados de desempenho estão apresentados na tabela 1. Não houve interação $(P>0,05)$

Ciência Rural, v.38, n.6, set, 2008. 
Tabela 1 - Consumo de ração (CR), ganho de peso (GP) e conversão alimentar (CA) dos frangos de um a 21 dias, alimentados com dietas de diferentes granulometrias, contendo ou não enzima Fitase.

\begin{tabular}{llll}
\hline & CR $(\mathrm{g})$ & GP $(\mathrm{g})$ & CA $(\mathrm{g} / \mathrm{g})$ \\
\hline \multicolumn{3}{c}{ Fitase } \\
Sem fitase & 1081 & 796 & 1,359 \\
Com fitase & 1067 & 783 & 1,363 \\
Probabilidade $>$ F & 0,384 & 0,191 & 0,828 \\
& Granulometria & \\
$430 \mu \mathrm{m}$ & 1087 & 780 & 1,392 \\
$680 \mu \mathrm{m}$ & 1061 & 798 & 1,330 \\
Probabilidade $>$ F & 0,109 & 0,05 & 0,003 \\
F x DGM & 0,427 & 0,148 & 0,606 \\
CV $(\%)$ & 3,45 & 4,22 & 4,94 \\
\hline
\end{tabular}

entre a inclusão de fitase e a granulometria para as variáveis estudadas. As aves que receberam dietas com DGM $680 \mu \mathrm{m}$ tiveram maior ganho de peso $(\mathrm{P}=0,05)$ e melhor conversão alimentar $(\mathrm{P}=0,003)$ quando comparadas aos frangos alimentados com dietas com DGM 430 $\mu \mathrm{m}$. Esta diferença pode ser explicada pelo fato de partículas maiores reduzirem o peristaltismo, estimularem o intiperistaltismo, estimularem favoravelmente a redução do $\mathrm{pH}$ gástrico e o aumento do $\mathrm{pH}$ intestinal, promover aumento das vilosidades da mucosa intestinal e melhorar a digestibilidade de nutrientes (RIBEIRO et al., 2002; DAHLKE etal., 2001 e 2003).

Não foi verificada diferença $(\mathrm{P}>0,05)$ no consumo de ração, quando comparadas as granulometrias, embora não sejam raros trabalhos na literatura que demonstram maior consumo para dietas de texturas mais grosseiras, tanto na fase inicial (NIR et al., 1990, RIBEIRO et al., 2002), quanto no período total de criação (DAHLKE et al., 2001; LÓPEZ \& BAIÃO, 2004). A granulometria máxima empregada neste teste foi menor que as observadas nos trabalhos citados, bem como o intervalo entre a granulometria máxima e mínima, que também foi menor do o que observado na literatura explicando possivelmente, esta discrepância.

A redução dos níveis de fósforo disponível e de cálcio na dieta não proporcionou diferença significativa para $\mathrm{CR}, \mathrm{GP}$ e CA. O fato indica uma maior hidrólise promovida pelo fitato e conseqüente disponibilização destes minerais, não havendo necessidade de aumento no consumo para compensar a redução destes na dieta. Também não foram observadas diferenças significativas nos coeficientes de metabolizabilidade da MS e da energia (Tabela 2). ZANOTTO et al. (1994) avaliaram a influência da variação do DGM das partículas de milho sobre os valores de energia metabolizável e também concluíram que o DGM não age de forma significativa sobre esta variável.

Houve interação entre os fatores fitase e granulometria nos coeficientes de metabolisabilidade da proteína bruta e biodisponibilidade do Ca e P(Tabela 2). Avaliando o uso da fitase, isoladamente nas dietas com diferentes granulometrias (Tabela 3, 4 e 5), verifica-se que a adição da fitase aumentou o coeficiente de metabolisabilidade da proteína bruta e a biodisponibilidade do cálcio somente nas dietas de menor granulometria $(430 \mu \mathrm{m})$. Nas dietas isentas de Fitase, houve um maior coeficiente de digestibilidade da proteína e biodisponibilidade do Cálcio para rações de maior DGM.

No desdobramento da interação entre os fatores granulometria e fitase, para coeficiente de biodisponibilidade do fósforo (Tabela 6), observa-

Tabela 2 - Coeficiente de metabolisabilidade da matéria seca (MS), proteína bruta (PB), energia bruta e coeficiente de biodisponibilidade do cálcio $(\mathrm{Ca})$, fósforo $(\mathrm{P})$ em dietas de diferentes granulometrias contendo ou não enzima fitase.

\begin{tabular}{|c|c|c|c|c|c|}
\hline & MS (\%) & PB (\%) & $\mathrm{Ca}(\%)$ & $\mathrm{P}(\%)$ & $\operatorname{EM}\left(\mathrm{kcal} \mathrm{kg}^{-1}\right)$ \\
\hline \multicolumn{6}{|c|}{ Fitase } \\
\hline Sem fitase & 95,2 & 78,3 & 74,9 & 78,1 & 3004 \\
\hline Com fitase & 95,4 & 78,8 & 75,8 & 79,0 & 3009 \\
\hline Probabilidade $>$ F & 0,265 & 0,346 & 0,130 & 0,082 & 0,716 \\
\hline \multicolumn{6}{|c|}{ Granulometria } \\
\hline $430 \mu \mathrm{m}$ & 95,2 & 77,1 & 73,9 & 78,8 & 3003 \\
\hline $680 \mu \mathrm{m}$ & 95,4 & 80,0 & 76,8 & 78,3 & 3011 \\
\hline Probabilidade $>$ F & 0,241 & 0,001 & 0,001 & 0,330 & 0,542 \\
\hline $\mathrm{F} \times \mathrm{DGM}$ & 0,251 & 0,001 & 0,020 & 0,003 & 0,196 \\
\hline CV $(\%)$ & 6,12 & 4,26 & 5,87 & 4,65 & 6,12 \\
\hline
\end{tabular}

Ciência Rural, v.38, n.6, set, 2008. 
Tabela 3 - Composição calculada das dietas experimentais.

\begin{tabular}{lcc}
\hline & & \\
Ingredientes & Sem fitase & Com fitase \\
\hline Milho & 50,14 & 50,14 \\
Farelo de soja & 41,77 & 41,77 \\
Óleo vegetal & 3,98 & 3,98 \\
Fosfato Bi-Ca & 1,76 & 1,21 \\
Calcário & 1,04 & 1,11 \\
Sal comum & 0,47 & 0,47 \\
Premix Min/Vit & 0,40 & 0,40 \\
DL-metionina & 0,31 & 0,31 \\
L-Lisina & 0,02 & 0,02 \\
Fitase & - & 0,01 \\
Caulin & 0,11 & 0,58 \\
-----------------Composição calculada--------------------- \\
EM (kcal kg-1) & 3.000 & 3.000 \\
PB (\%) & 23,00 & 23,00 \\
Ca (\%) & 0,95 & 0,85 \\
P disponível (\%) & 0,45 & 0,35 \\
Lisina (\%) & 1,32 & 1,32 \\
Lisina dig. (\%) & 1,18 & 1,18 \\
Metionina (\%) & 0,70 & 0,70 \\
Metionina dig. (\%) & 0.62 & 0.62 \\
Met + cist. (\%) & 1,05 & 0,05 \\
Met + cist. dig. (\%) & 0,94 & \\
Treonina (\%) & 0,89 & 0,79 \\
Treonina dig.(\%) & 0,79 & \\
Na (\%) & 0,20 & \\
\hline & & \\
\hline & & \\
\hline
\end{tabular}

se uma melhora nesta variável com a adição da fitase, somente nas rações de menor granulometria $(430 \mu \mathrm{m})$. Quando avaliada somente a granulometria, em dietas isentas da enzima Fitase, não houve diferença para o coeficiente de biodisponibilidade do Fósforo.

Os maiores coeficientes de metabolizabilidade da proteína e o coeficiente de

Tabela 4 - Desdobramento da interação entre fitase e granulometria para o coeficiente de metabolisabilidade da proteína bruta de dietas de diferentes granulometrias contendo ou não enzima fitase.

\begin{tabular}{lll}
\hline Fitase & - -----Granulometria------- \\
& 430 & 680 \\
\hline Com & $78,4^{\mathrm{A}}$ & 79,2 \\
Sem & $75,8^{\mathrm{bB}}$ & $80,7^{\mathrm{a}}$ \\
\hline
\end{tabular}

Médias seguidas de letras maiúsculas na mesma coluna diferem entre si (Tukey 5\%)

\begin{tabular}{ccc} 
Tabela 5 - & $\begin{array}{l}\text { Desdobramento da interação entre fitase e } \\
\text { granulometria para o coeficiente de } \\
\text { biodisponibilidade do cálcio de dietas de } \\
\text { diferentes granulometrias contendo ou não enzima } \\
\text { fitase. }\end{array}$ \\
\hline Fitase & - ----Granulometria------- \\
Com & 430 & 680 \\
Sem & $74,7^{\mathrm{A}}$ & 76,9 \\
\hline
\end{tabular}

Médias seguidas de letras maiúsculas na mesma coluna diferem entre si (Tukey 5\%)

biodisponibilidade do Cálcio e Fósforo, nas dietas de maior DGM, contribuem para elucidar o melhor ganho de peso e a conversão alimentar das aves alimentadas com dietas de textura mais grosseira.

Da mesma forma, os melhores resultados para os coeficientes de metabolizabilidade da Proteína e a biodisponibilidade do Cálcio e Fósforo, com adição da enzima Fitase, nas dietas de menor granulometria, podem explicar a equalização do consumo das aves e conseqüentemente a não observância de diferença significativa para esta variável.

\section{CONCLUSÕES}

Dietas de maior granulometria melhoram o ganho de peso e a conversão alimentar de frangos de corte na fase inicial. Os coeficientes de metabolisabilidade da proteína bruta e os coeficientes de biodisponibilidade de cálcio e fósforo são melhorados quando utilizadas dietas de textura mais grosseira. A utilização de fitase aumenta a eficiência de uso de nutrientes da ração e melhora o desempenho de frangos de corte.

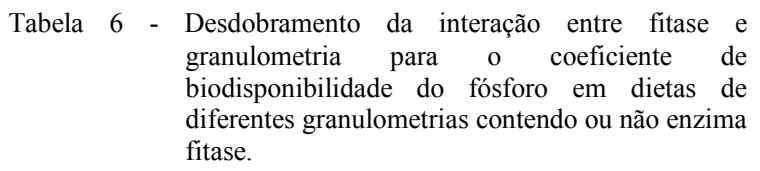
granulometria para o coeficiente de biodisponibilidade do fósforo em dietas de diferentes granulometrias contendo ou não enzima fitase.

\begin{tabular}{lll}
\hline \multirow{2}{*}{ Fitase } & ------- Granulometria-------- \\
& 430 & 680 \\
\hline Com & $80,0^{\mathrm{Aa}}$ & $78,6^{\mathrm{b}}$ \\
Sem & $77,5^{\mathrm{B}}$ & 77,9 \\
\hline
\end{tabular}

Médias seguidas de letras maiúscula na mesma coluna diferem entre si (Tukey 5\%).

Ciência Rural, v.38, n.6, set, 2008. 


\section{REFERÊNCIAS}

ASSOCIATION OF OFFICIAL ANALYTICAL CHEMISTS AOAC. Official methods of analysis. 12.ed. Washington, 1990. 1098p.

BOLING, S.D. et al. The effects of citric acid on phytasephosphorus utilization in young chicks and pigs. Journal of Animal Science, v.78, n.3, p.682-689, 2000.

DAHLKE, F. et al. Tamanho da partícula do milho e forma física da ração e seus efeitos sobre o desempenho e rendimento de carcaça de frangos de corte. Revista Brasileira de Ciência Avícola, v.3, p.211-217, 2001

DAHLKE, F. et al. Effect of corn particle size and physical form on the diet on the gastrointestinal structures of broiler chickens. Revista Brasileira de Ciência Avícola, v.5, p.6167, 2003

LOPEZ, C.A.A.; BAIÃO, N.C. Efeito do tamanho da partícula e da forma física da ração sobre o desempenho, rendimento de carcaça e peso dos órgãos digestivos de frangos de corte.
Arquivos Brasileiros de Medicina Veterinária e Zootecnia, v.56, p.214-221, 2004

NIR, I.; J.P. et al. Effect of particle size of sorghum grains on feed intake and performance of young broilers. Poultry Science, v.69, p.2177-2184, 1990.

RIBEIRO, A.M.L. et al. Granulometria de milho em rações de crescimento de frangos de corte e seu efeito no desempenho e metabolismo. Revista Brasileira de Ciência Avícola, v.4, p.41-47, 2002.

SAS. Statistical analysis system. User's guide: Stat. Version 6.11ed. Cary, 1996. 842p.

ZANOTTO, D.L. et al. Efeito do grau de moagem no valor energético do milho para frangos de corte. In: REUNIÃO ANUAL DA SOCIEDADE BRASILEIRA DE ZOOTECNIA, 1994, Maringá, PR. Anais... Maringá, Sociedade Brasileira de Zootecnia, 1994. 57p.

ZANOTTO, D.L.; BELLAVER, C. Método de determinação da granulometria de ingredientes para uso de rações de suínos e aves. Concórdia: EMBRAPA-CNPSA, 1996. 12p. (Comunicado Técnico, 15). 